\title{
"Da 'A Arqueologia do Saber' à Genealogia da Ética" ou Quando o futuro repete o passado: o cuidado de si e as políticas públicas de saúde na atualidade
}

\author{
"From 'The Archaeology of Knowledge' to the Genealogy of Ethics" or When the future \\ repeats the past: the care of the self and public health policies today
}

\author{
Bruno Franceschini ${ }^{1}$ \\ Universidade Federal de Goiás, Regional Catalão - UFG \\ franceschini.bf@gmail.com
}

\begin{abstract}
Resumo: Este artigo tem por objetivo discutir acerca das práticas do cuidado de si por meio da análise de campanhas veiculadas pelo Ministério da Saúde no tocante às infecções sexualmente transmissíveis em uma perspectiva arquegenealógica no escopo dos estudos discursivos de orientação foucaultiana. Dito isso, pretende-se analisar como há o delineamento do exercício de práticas de governamentalidade do corpo da população pelo funcionamento da biopolítica e do biopoder e como, frente a essas estratégias de poder, ocorre o cuidado de si em um movimento de práticas de liberdade em relação a práticas conservadoras exercidas por tais campanhas, as quais normatizam e normalizam os corpos e as condutas dos sujeitos no que tange à sexualidade. Os resultados deste estudo indicam que a educação sexual funciona como um modo de cuidado de si para que os sujeitos possam se constituir como bons governantes de suas condutas.
\end{abstract}

Palavras-chave: Análise do Discurso; Michel Foucault; Arquegenealogia; Cuidado de si; Prática de liberdade.

\begin{abstract}
This article aims to discuss about the care of the self practices through the analysis of media campaigns carried out by the Ministry of Health regarding sexually transmitted infections from an archegenealogical perspective within the scope of Foucauldian discursive studies. That said, this study intends to analyze how there is the delineation of the exercise of governmentality practices of the body of the population by the functioning of biopolitics and biopower and how, in face of these power strategies, the care of the self occurs in a movement of practices of liberty in relation to conservative practices exerted by such campaigns, which normatize and normalize the bodies and the conduct of the subjects regarding sexuality. The results of this study indicate that sex education works as a way of the care of the self so that the subjects can be constituted as good rulers of their behavior.
\end{abstract}

Keywords: Discourse Analysis; Michel Foucault; Archaegenealogy; Care of the self; Liberty practice.

\footnotetext{
${ }^{1}$ Professor Adjunto da Unidade Acadêmica Especial de Letras e Linguística e do Programa de Pós-Graduação em Estudos da Linguagem da Universidade Federal de Goiás - Regional Catalão.
} 
Bruno Franceschini. “Da 'Arqueologia do Saber' à Genealogia da Ética ou Quando o futuro repete o passado: o cuidado de si e as políticas públicas de saúde na atualidade

\section{Introdução}

Este texto parte de um incômodo que se deu quando do contato com um vídeo da campanha de prevenção às Infecções Sexualmente Transmissíveis (ISTs) feito pelo Ministério da Saúde lançado em outubro de 2019. A partir da circulação de tal campanha, tanto em material audiovisual quanto em mídias digitais, procuramos pensar nessas materialidades de modo a realizar uma breve arqueologia das campanhas feitas pelo Ministério no que tange à prevenção às ISTs bem em como o sujeito exerce um cuidado de si frente a uma prática discursiva institucional-médica conservadora.

Assim, levantamos algumas questões para a discussão que aqui se pretende: A) Como, no âmbito dos conceitos de discurso, história e memória, ocorre a retomada de enunciados que remetem à condução das condutas sexuais não por um cuidado da vida, mas por uma política pública de saúde que instaura o medo?; B) Como pensar, no escopo da genealogia da ética, o exercício do cuidado de si frente às ISTs (Infecções Sexualmente Transmissíveis)?; C) Como analisar, pensando com Foucault nos Ditos e Escritos IX, esse "cuidado de si que remete a um estado político e erótico ativo, como um elo que se fixa entre o cuidado de si e a atividade política"?; e D) Será possível o exercício de práticas de liberdade no campo desse discurso de combate a ISTs quando a temática da sexualidade toca o corpo e a população e nessa relação há a incidência do exercício do poder disciplinar, da biopolítica e do biopoder?

De modo a responder a essas perguntas, este artigo encontra respaldo teóricometodológico nos estudos de Michel Foucault para que seja possível a realização dos procedimentos de tratamento dos enunciados coletados frente à análise do corpus, para o qual estabelecemos três trajetos temáticos (GUILHAUMOU; MALDIDIER, 1997), quais sejam: 1) Propagandas antigas do Ministério da Saúde; 2) Propagandas cujo objeto alvo é a sífilis; 3) Reportagens atuais com relação à educação sexual.

\section{Das condições de possibilidade dos discursos sobre as ISTs no Brasil}

De modo a circunscrever as condições de possibilidade para os enunciados que serão analisados, apresentamos, neste primeiro momento, enunciados retirados do "Boletim 
Bruno Franceschini. “Da ‘Arqueologia do Saber' à Genealogia da Ética ou Quando o futuro repete o passado: o cuidado de si e as políticas públicas de saúde na atualidade

Epidemiológico Súfilis 2019²,, elaborado pelo Governo Federal. Neste documento, são apresentados dados com relação às questões epidemiológicas da sífilis e, segundo este documento: "espera-se que o presente Boletim auxilie a disseminação de informações, como uma das bases da construção de uma saúde coletiva que se vale das evidências geradas a partir da prática da epidemiologia em serviço” (BRASIL, p. 03, 2019). Com relação à nomenclatura de DST para IST, segundo o Ministério da Saúde, a Organização Mundial de Saúde já faz uso desse termo e a justificativa para essa mudança reside no fato de que, conforme expresso na página do governo federal: “A denominação 'D', de 'DST', vem de doença, que implica em sintomas e sinais visíveis no organismo do indivíduo. Já 'Infecções' podem ter períodos assintomáticas ou se mantém assintomáticas durante toda a vida do indivíduo"3.

Para a constituição do arquivo deste breve estudo, delimitamos a coleta dos enunciados somente na página do Ministério da Saúde, na aba "Campanhas"4, a partir da palavra-chave "sífilis e poucas são as campanhas que abordam as infecções de modo geral, tanto que na página há apenas 3 campanhas, veiculadas entre 2013 e 2017, que tratam da sífilis, uma IST que está fora de controle, seja por falta de penicilina ou pela recusa à prevenção e alcança seus maiores índices desde 2010, registrando aumento de $30 \%$ de 2017 para 2018. Já as demais campanhas têm como foco a AIDS e contabilizam cerca de 3 páginas de mídia institucional, com centenas de mídias digitais.

Imagem 1 - Aba “Campanhas” na página do Ministério da Saúde

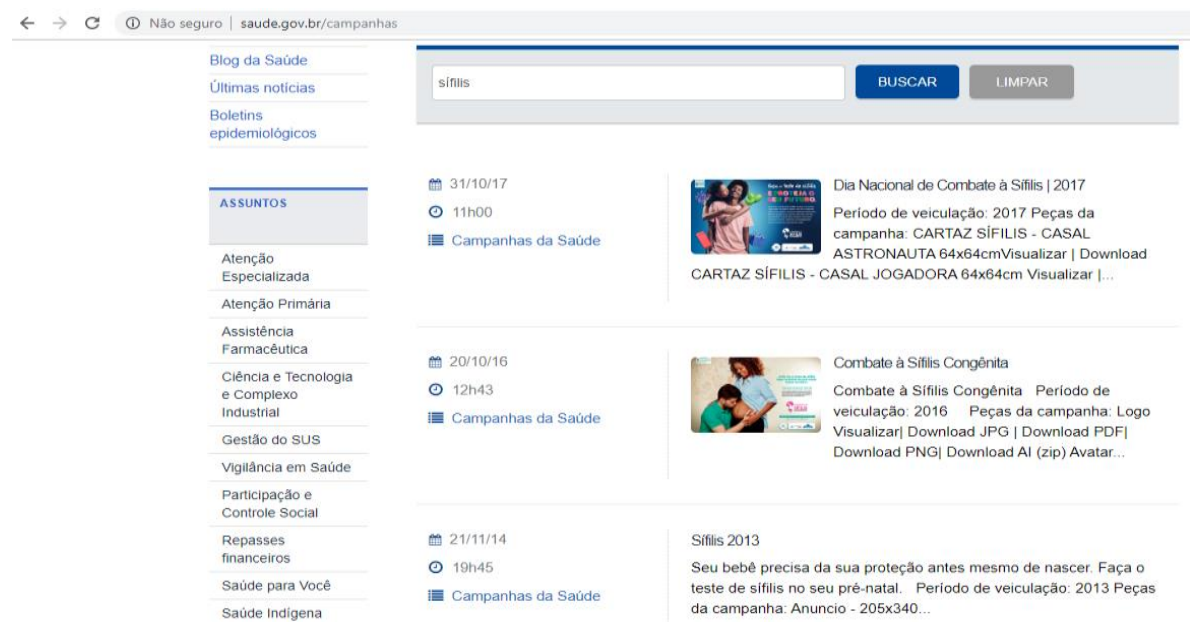

\footnotetext{
${ }^{2}$ Disponível em: <http://www.aids.gov.br/pt-br/pub/2019/boletim-epidemiologico-sifilis-2019>. Acesso em: 7 nov. 2019.

${ }^{3}$ Disponível em: <https://telelab.aids.gov.br/index.php/2013-11-14-17-44-09/item/519-departamento-passa-autilizar-nomenclatura-ist-no-lugar-de-dst>. Acesso em: 7 nov. 2019.

${ }^{4}$ Disponível em: 〈http://www.saude.gov.br/campanhas〉. Acesso em: 7 nov. 2019.
} 
Bruno Franceschini. “Da ‘Arqueologia do Saber' à Genealogia da Ética ou Quando o futuro repete o passado: o cuidado de si e as políticas públicas de saúde na atualidade

Imagem 2 - Taxa de detecção de sífilis adquirida

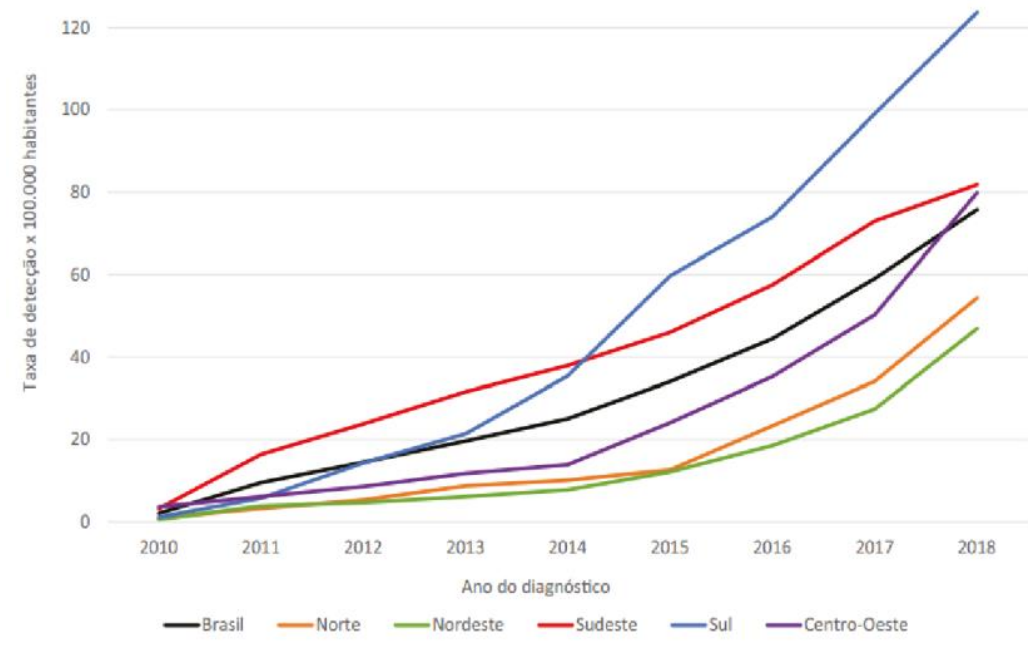

Fonte: Sistema de Informaçăo de Agravos de Notificaçăo (Sinan), atualizado em 30/06/2019. FGURA 5 Taxa de detecção (por 100.000 habitantes) de síflis adquirida, segundo regiāo de residência por ano de diagnóstico. BRASIL, 2010 A 2018

\section{Uma arqueologia da sífilis}

- 158.051 casos notificados em 2018;

- 75,8 casos $/ 100.000$ habitantes;

- 62.599 casos de sífilis em gestantes (taxa de detecção de 21,4/1.000 nascidos vivos);

- 26.219 casos de sífilis congênita (taxa de incidência de 9,0/1.000 nascidos vivos);

- 241 óbitos por sífilis congênita (taxa de mortalidade de 8,2/100.000 nascidos vivos).

No texto "As relações de poder perpassam para o interior dos corpos", Foucault (2014, p. 38) argumenta que:

Se o poder atinge o corpo, não é porque ele foi inicialmente interiorizado na consciência das pessoas. Há uma rede de biopoder, de somatopoder que é, ela mesma, uma realidade a partir da qual nasce a sexualidade como fenômeno histórico e cultural no interior do qual, ao mesmo tempo, nós nos reconhecemos e nos perdemos.

Então, que poder é esse que atinge o corpo? Que poder é esse que visa proteger o corpo e a população? Como analisar o discurso das ISTs que perpassa a sexualidade no âmbito desses enunciados? Assim, pensando nas práticas de poder do saber médico e das políticas públicas de saúde, analisamos tais discursos sob a ótica de, "pressões que a própria organização da cidade exerce sobre a sexualidade, portanto sobre a procriação; as pressões que se exercem sobre a higiene das famílias" (FOUCAULT, 2016 p. 211). Com base nos dados apresentados, observamos que a preocupação do governo com relação à sífilis se dá em decorrência do aumento exponencial de casos, tanto de infecção adquirida quanto congênita, o que implica uma urgência do Estado em responder à epidemia, considerando os efeitos da infecção no corpo social, tal como o funcionamento de um dispositivo. Neste caso, um dispositivo de sexualidade. 
Bruno Franceschini. “Da ‘Arqueologia do Saber' à Genealogia da Ética ou Quando o futuro repete o passado: o cuidado de si e as políticas públicas de saúde na atualidade

Assim, de modo a descrever as condições de possibilidade dos enunciados em análise, passamos a discussão agora sobre as quatro características relacionadas à análise arqueológica, a saber: estabelecimento de séries, descontinuidade, história nova e o arquivo, como elencadas em A Arqueologia do Saber. Esses quatro elementos estão imbricados a um outro que os perpassa: o acontecimento discursivo, conceito este que questiona a regularidade, a continuidade e pressupõe a dispersão dos discursos.

Sobre o acontecimento discursivo, é preciso ressaltar que, em consonância com o pensamento foucaultiano, concebemos o discurso como produto de elementos heterogêneos, o que confere o seu caráter descontínuo e de dispersão de enunciados, e que esse conceito de acontecimento nos permite pensar as condições de possibilidade do discurso em suas condições de existência e de materialidade. Apresento, então, o vídeo ${ }^{5}$ veiculado há duas semanas pelo Ministério da Saúde de modo a pensar tal materialidade como um acontecimento que possibilita a retomada dos discursos acerca da prevenção das infecções sexualmente transmissíveis, cuja adoção dessa nomenclatura se deu em 2016.

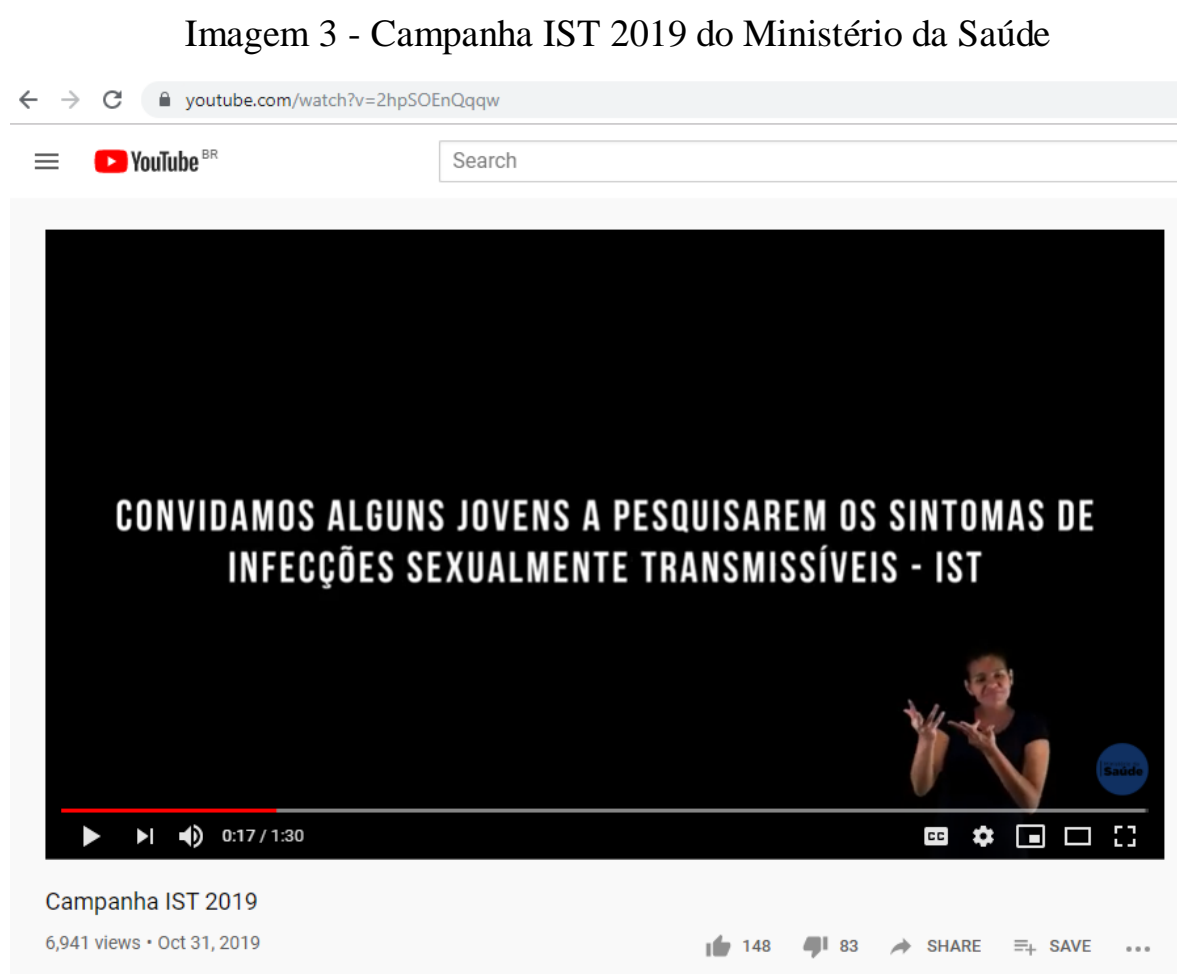

No livro "Em Defesa da Sociedade", Foucault (2016) explica como a sexualidade está ligada ao corpo e à população e é com base nessa discussão que pretendemos descrever e interpretar como o discurso sobre as ISTs tocam o sujeito, tanto no plano individual

\footnotetext{
${ }^{5}$ Disponível em: <https://www.youtube.com/watch?v=2hpSOEnQqqw〉. Acesso em: 7 nov. 2019.
} 
quanto no coletivo, no funcionamento discursivo de uma política pública conservadora que visa conduzir as condutas, os corpos, sob um regime de poder normalizador e regulamentador, apresentando a sífilis, gonorreia, clamídia, cancro mole, dentre outras em uma perspectiva de uma sexualidade que foge à norma. Para Foucault (2016, p. 212),

[...] quando a sexualidade é indisciplinada e irregular, tem sempre duas ordens de efeitos: um sobre o corpo, sobre o corpo indisciplinado que é imediatamente punido por todas as doenças individuais que o devasso sexual atrai sobre si [...] e tem efeitos no plano da população, uma vez que se supõe que aquele que foi devasso sexualmente tem uma hereditariedade.

Como questiona o autor: "que singular existência é esta que vem à tona no que se diz e em nenhuma outra parte?" (FOUCAULT, 2009, p. 31). No trabalho de descrição e de interpretação dos discursos, procuramos, então, analisar o que possibilitou a circulação de enunciados sobre esse objeto, tendo em vista que "o novo não está no que é dito, mas no acontecimento de sua volta" (FOUCAULT, 2008, p. 26). Nesse movimento, procuramos estabelecer a pertinência dos diversos acontecimentos discursivos que possibilitaram a emergência deste vídeo como um acontecimento discursivo, considerando o estabelecimento de séries e os jogos enunciativos entre os sujeitos que falam nesses enunciados.

Pautados no conceito de arquivo proposto por Foucault (2009), conceito esse que se refere ao funcionamento do discurso no âmbito daquilo que pode circular, que pode emergir enquanto acontecimento discursivo e que opera com o sistema de enunciabilidade, é o que vai determinar seu modo de funcionamento e a atualidade do enunciado. Assim, aventamos que tal funcionamento se dá tendo em vista as condições de possibilidade frente aos discursos na política atual brasileira, especialmente no que diz respeito à sexualidade e à educação sexual, o que será mais amplamente discutido a seguir.

\section{Primeiro trajeto temático: propagandas das décadas de 80 e 90 relacionadas às ISTs}

O primeiro trajeto recortado do arquivo da pesquisa é composto por três enunciados de propagandas institucionais ${ }^{6}$ veiculadas nos anos 80/90 cujo foco de prevenção era a

\footnotetext{
${ }^{6}$ Propaganda 1 - Disponível em: 〈https://collections.nlm.nih.gov/catalog/nlm:nlmuid-101451692-img〉. Acesso em: 7 nov. 2019.
} 
Bruno Franceschini. “Da ‘Arqueologia do Saber' à Genealogia da Ética ou Quando o futuro repete o passado: o cuidado de si e as políticas públicas de saúde na atualidade

AIDS. Nesses enunciados, analisamos que há um delineamento do cuidado de si com relação às práticas sexuais e, como discute Foucault ao longo dos três volumes da História da Sexualidade, observamos o funcionamento de um regime de afrodisia em intersecção com uma prática normalizadora e regulamentadora da sexualidade, em que há um imperativo que diz que o sujeito pode manter relações sexuais, mas com segurança, por meio da utilização de preservativo.

Imagem 4 - Propaganda da década de 1990

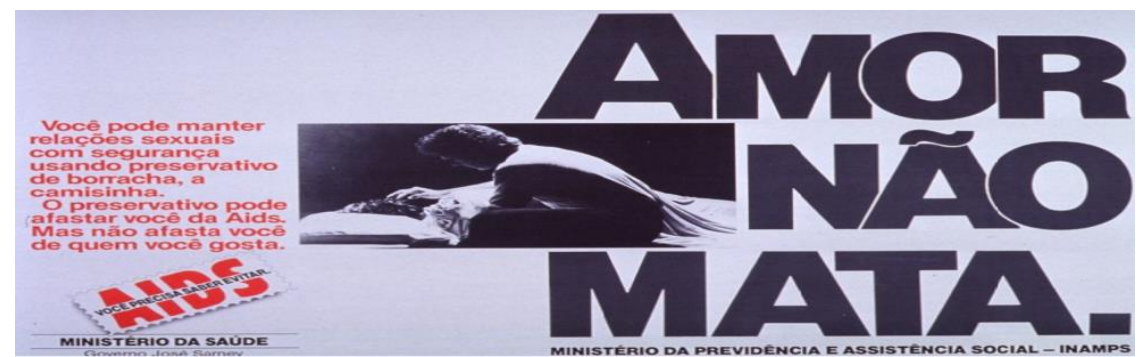

Imagem 5 - Propaganda da década de 1980

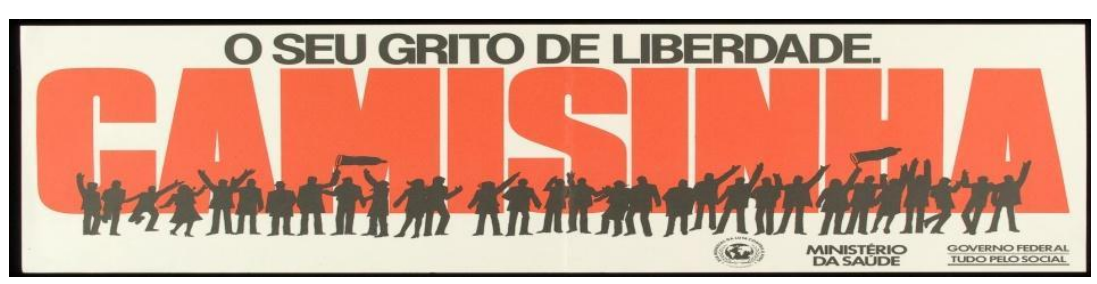

Imagem 6 - Propaganda da década de 1980

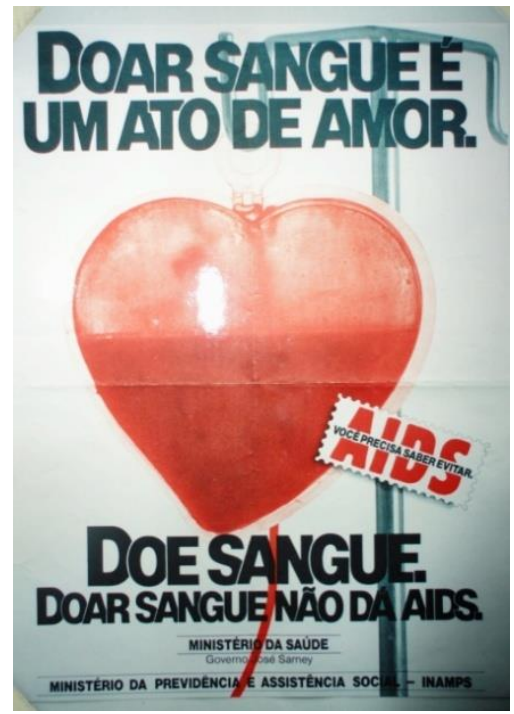

Propaganda 2 - Disponível em: <https://collections.nlm.nih.gov/catalog/nlm:nlmuid-101438905-img〉. Acesso em: 7 nov. 2019.

Propaganda 3 - Disponível em: <https://collections.nlm.nih.gov/catalog/nlm:nlmuid-101438671-img〉. Acesso em: 7 nov. 2019. 
Nesse jogo enunciativo, analisamos os enunciados pelo conceito de afrodisia no âmbito de um cuidado de si com relação à condução da conduta sexual, como objeto de uma reflexão moral na dinâmica do tripé desejo - ato - prazer, elementos esses que constituem o "grão da experiência dos afrodisia" (FOUCAULT, 2017, p. 54). Ou seja, nos enunciados em análise, analisamos que a questão ética é colocada quando a responsabilidade pela prevenção da AIDS é confrontada com os prazeres, remetendo-nos a Foucault: "com que força se é levado pelos prazeres e pelos desejos?"

Ainda sobre os efeitos produzidos no sujeito acerca dos enunciados, analisamos também que o enunciado institucional é instaurador, um motor, para o cuidado de si, especialmente no que diz respeito ao sujeito institucional ministério da saúde, órgão governamental que é constituído, majoritariamente, pelo saber médico. No escopo da prática discursiva médica e do diálogo com o cuidado de si, o médico é quem tem "a capacidade de dar conselhos sobre a maneira pela qual é necessário fazer uso dos prazeres da mesa e da cama [...] como obter o gozo sem que isso resulte num desregramento" (FOUCAULT, 2017, p. 63).

Para a finalização desta primeira série enunciativa, concluímos que, nessas primeiras propagandas, o Governo Federal visa à promoção de um cuidado de si, no entanto, não vislumbramos, neste momento, um cuidado de si que conduza às práticas de liberdade. Pelo contrário, lemos tais enunciados como um cuidado de si por prescrições regulamentadoras e normalizadoras das condutas, em um falseamento da liberdade em que há, na verdade, a condução da conduta da população, no funcionamento de técnicas de si que mobilizam a proibição e à renúncia. Como explica Sanches (2014), na análise feita acerca das propagandas ministeriais sobre o HIV, "a prática do sexo livre é reprimida pelo poder político, o qual se vale de uma biopolítica reguladora das práticas do cuidado de si. $\mathrm{O}$ desejo do corpo pelo próprio corpo deve ser controlado a fim de se evitar práticas sexuais de alto risco de contaminação.", devendo o sujeito olhar para si, praticar o cuidado de si, adotando determinadas práticas, como a redução de parceiros e recusa à promiscuidade.

\section{Segundo trajeto temático: a sífilis como objeto de discurso}

Neste segundo trajeto, os enunciados estão compreendidos em campanhas de 2013 a 2019 e tais materialidades evidenciam quatro sujeitos: o casal heterossexual a espera de 
Bruno Franceschini. “Da ‘Arqueologia do Saber' à Genealogia da Ética ou Quando o futuro repete o passado: o cuidado de si e as políticas públicas de saúde na atualidade

uma criança, a mulher gestante, um casal heterossexual e um rapaz em idade sexual ativa. Ao analisarmos nosso arquivo, observamos como a questão da saúde da população é colocada nas campanhas anteriores. Em tais enunciados observamos a produção de sentidos que evidenciam o funcionamento de uma biopolítica e de um biopoder, cujo foco é a vida e o domínio sobre a mortalidade. Como teoriza Foucault (2017, p. 152), é preciso "investir sobre a vida, de cima a baixo". Nos enunciados em análise: sobre a vida, da monogamia à reprodução.

Imagem 7 - Campanhas de combate à sífilis, 2016
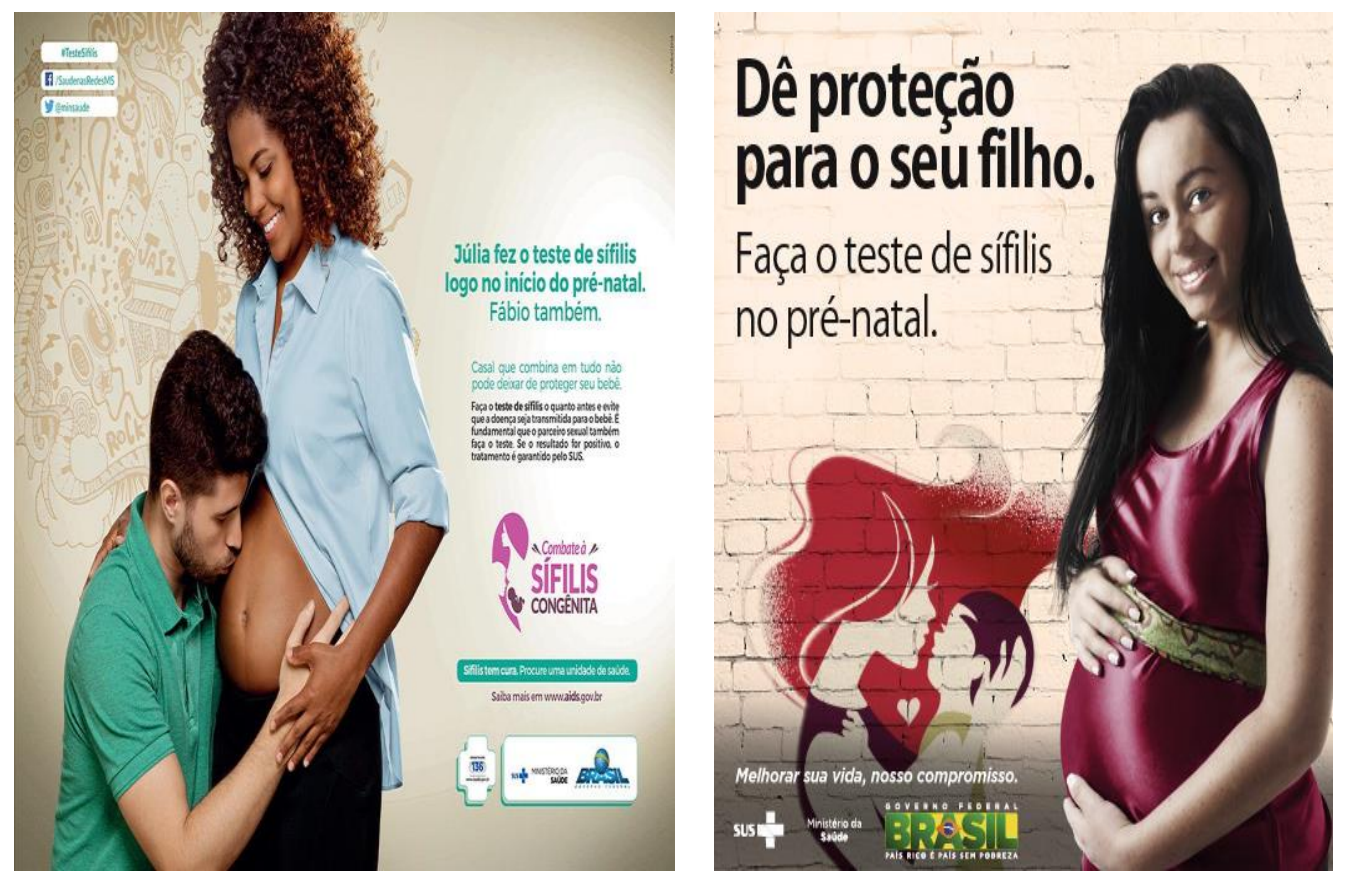

O sujeito institucional que fala nesses enunciados é produtor de discursos que alcançam o corpo e a população em mecanismos disciplinares e regulamentadores. Nesse sentido, o funcionamento discursivo da prática discursiva médica é de normatizar e de normalizar esses corpos em sua individualidade e multiplicidade. Para Foucault (2016, p. 213):

A norma é o que pode tanto se aplicar a um corpo que se quer disciplinar quanto a uma população que se quer regulamentar. [...] que se estende do orgânico ao biológico, do corpo à população, mediante o jogo duplo das tecnologias de disciplina, de uma parte, e das tecnologias de regulamentação de outra.

Nos enunciados desta segunda série, observamos como a moral cristã funciona, mobilizando o dispositivo de aliança, regulamentando a prática da sexualidade nessa 
Bruno Franceschini. “Da 'Arqueologia do Saber' à Genealogia da Ética ou Quando o futuro repete o passado: o cuidado de si e as políticas públicas de saúde na atualidade

perspectiva, com a prática sexual realizada pelo casal, tendo como fim a reprodução. Nesse sentido, acerca da constituição da população, Foucault (2017, p. 31) explica que

[...] os governos percebem que não têm que lidar simplesmente com sujeitos, nem mesmo com um "povo", porém com uma "população", com seus fenômenos específicos e suas variáveis próprias: natalidade, morbidade, esperança de vida, fecundidade, estado de saúde, incidência das doenças, forma de alimentação e habitat.

Um fato a ser observado é que nas quatro campanhas veiculadas, apenas a última não aborda a questão da maternidade, o que nos indica uma maior preocupação dos governos anteriores com relação à manutenção da vida, à saúde da população enquanto, no atual governo, observamos a instauração de uma política pública que remete ao medo e, no tocante ao cuidado de si, à intemperança. Como diz Aristóteles, citado por Foucault (2017, p. 64): "Todo mundo, em certa medida, usufrui o prazer da mesa, do vinho e do amor, mas nem todos o fazem como convém". Nessa última campanha, especificamente, analisamos que o sujeito produzido em tal materialidade exerce sobre si não um cuidado ético, como no regime de afrodisia, mas uma moral cristã, "um reconhecimento da lei e de uma obediência à autoridade pastoral [...] a renúncia de si e uma pureza, cujo modelo deve ser buscado do lado da virgindade" (FOUCAULT, 2017, p. 111)

Imagem $8^{7}$ - Campanha do Dia Nacional de Combate à Sífilis, 2017

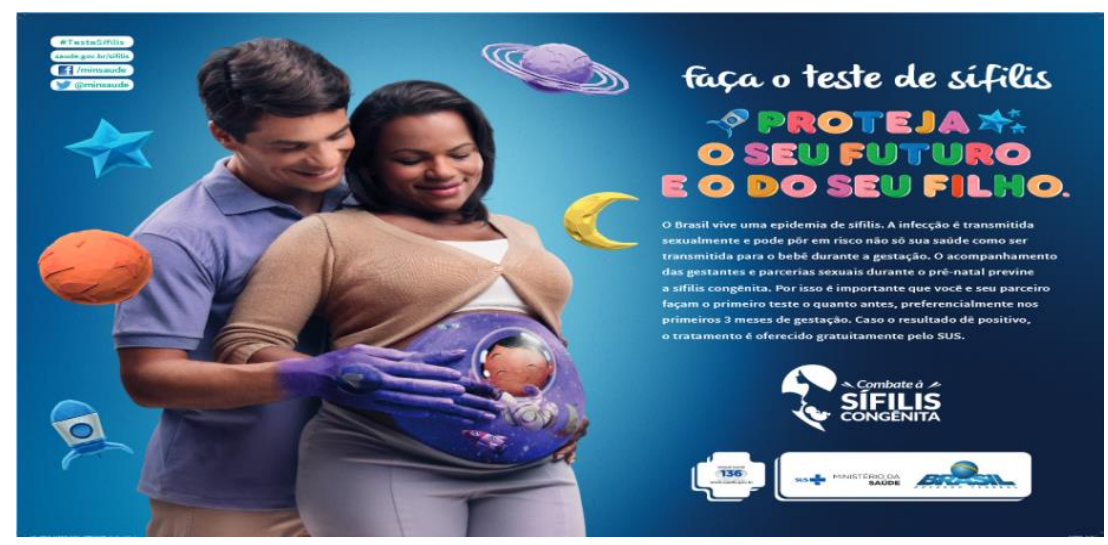

7 Disponível em: <http://www.saude.gov.br/campanhas/41752-dia-nacional-de-combate-a-sifilis-2017>. Acesso em: 07 nov. 2019. 
Bruno Franceschini. “Da ‘Arqueologia do Saber' à Genealogia da Ética ou Quando o futuro repete o passado: o cuidado de si e as políticas públicas de saúde na atualidade

Imagem $9^{8}$ - Campanha de IST, 2019

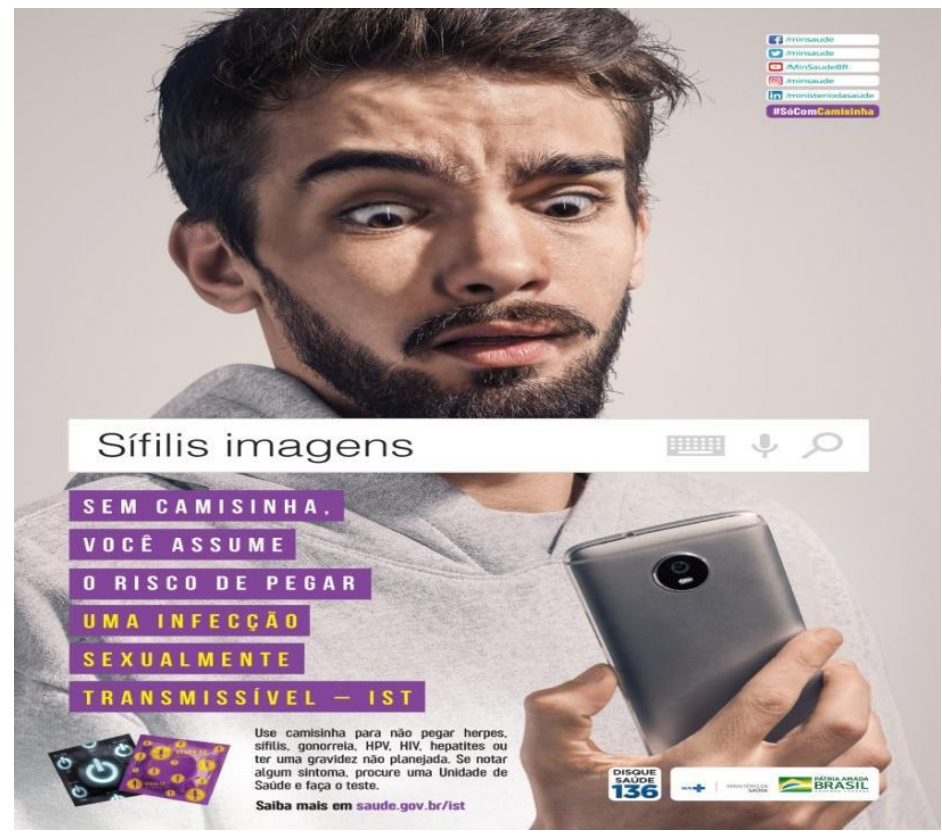

Assim, ao finalizarmos a leitura dos enunciados desta segunda série, partilhamos da posição de Sanches (2014, p. 55), para quem:

O olhar sobre o corpo e a regulamentação das práticas sexuais da população são, então, potencializados por meio do investimento do biopoder sobre os corpos e o emprego do dispositivo de sexualidade como ferramenta necessária ao combate da doença que se manifestava em grupos adeptos da liberdade sexual. Sobre esses indivíduos, é direcionado todo um olhar clínico, atentando, especialmente, para as regulações das práticas da sexualidade.

Isso evidencia a política adotada pelos governos anteriores e o atual com relação às práticas sexuais pautadas em condutas cisheteronormativas, como se apenas esses corpos merecessem o cuidado do Estado frente às políticas públicas de saúde para prevenção das ISTs, considerando a exclusão de todo um corpo social LGBT e centrando a prevenção somente para os sujeitos que visam a manutenção da estrutura vigente: pai, mãe e filhos. Dito isso, concluímos que o funcionamento da biopolítica e do biopoder, presentificados nos enunciados em análise, visam gerir a vida da população de forma a mantê-la saudável, viva, economicamente ativa e com taxas de natalidade positivas.

\footnotetext{
${ }^{8}$ Disponível em: <http://www.saude.gov.br/campanhas/45958-campanha-de-ist>. Acesso em: 7 nov. 2019.
} 
Bruno Franceschini. “Da 'Arqueologia do Saber' à Genealogia da Ética ou Quando o futuro repete o passado: o cuidado de si e as políticas públicas de saúde na atualidade

\section{Terceiro trajeto temático: a educação sexual para o exercício de práticas de liberdade}

Por fim, a última série enunciativa reside em enunciados coletados de jornais brasileiros os quais trazem manchetes ${ }^{9}$ que evidenciam os posicionamentos do atual governo frente ao desenvolvimento de políticas públicas relacionadas à sexualidade. Assim, pautado no escopo teórico escrito por Foucault no segundo volume da História da Sexualidade, realizamos a leitura desses enunciados sob a ótica do cuidado de si no que diz respeito aos princípios para o bom governante de modo a chegar ao final indicando caminhos para que esse cuidado de si frente às ISTs possa abrir caminho para o exercício de práticas de liberdade por meio da educação sexual nas escolas, para que os jovens, sujeitos em idade escolar possam exercer um cuidado de si pelo conhecimento de seu corpo, de suas práticas sexuais e, desse modo, alcançar a verdade de si.

A esse respeito, explica Foucault (2004, p. 5) que

[...] o cuidado de si permite ocupar na cidade, na comunidade ou nas relações interindividuais o lugar conveniente - seja para exercer uma magistratura ou para manter relações de amizade. Além disso, cuidado de si implica também a relação com um outro, uma vez que, para cuidar bem de si, é preciso ouvir as lições de um mestre.

Assim, amparados em Foucault (2004), analisamos que a aula de educação sexual é um modo de possibilitar um caminho para o conhecimento de si e exercício do cuidado de si, tendo como finalidade a prevenção de doenças e de abusos sexuais. Para o autor, o cuidado de si "poderá ser, ao mesmo tempo, senão um cuidado dos outros, pelo menos um cuidado de si benéfico para os outros." (FOUCAULT, 2004, p. 6). Analisamos ainda que, por meio do cuidado de si, exerce o que Foucault (2004, p. 9) conceitua como preceitos para um bom governante: "o cuidado de si aparece como condição pedagógica, ética e também ontológica para a constituição do bom governante. Constituir-se como sujeito que governa implica que se tenha se constituído como sujeito que cuida de si”.

\footnotetext{
9 Manchete 1 - Disponível em: <https://www1.folha.uol.com.br/educacao/2018/12/na-mira-de-bolsonaroeducacao-sexual-mira-de-doencas-a-gravidez-precoce.shtml>. Acesso em: 7 nov. 2019.

Manchete 2 - Disponível em: <https://exame.abril.com.br/brasil/modelo-no-mundo-departamento-decombate-ao-hiv-do-brasil-perde-status>. Acesso em: 7 nov. 2019.

Manchete 3 - <https://www1.folha.uol.com.br/equilibrioesaude/2019/03/caderneta-para-saude-daadolescente-sera-revista-diz-ministro-apos-criticas-de-bolsonaro.shtml>. Acesso em: 7 nov. 2019.

Manchete 4 - Disponível em: <https://www.dw.com/pt-br/governo-bolsonaro-preocupa-entidades-decombate-\%C3\%A0-aids/a-48530534>. Acesso em: 7 nov. 2019.
} 


\section{Alvo de Bolsonaro, educação sexual mira de doenças a gravidez precoce}

Aulas sobre o tema têm diferentes formatos e abordagens em escolas leigas e religiosas

\section{BRASIL}

Modelo no mundo, departamento de combate ao HIV do Brasil perde status

\section{Bolsonaro diz que vai recolher caderneta de saúde do adolescente}

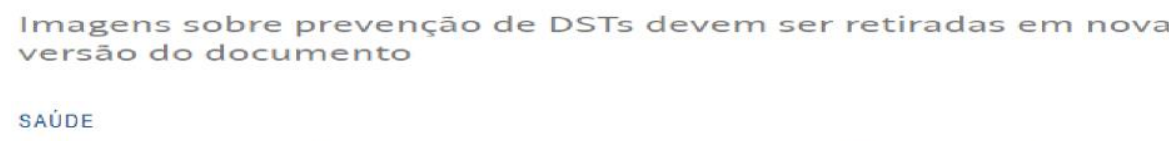

Novas medidas relacionadas à saúde, incluindo mudanças na Política Nacional de Drogas, acendem alerta vermelho para organizações, que temem retrocessos em direitos conquistados e na prevenção à doença.

Dito isso, nos enunciados desta última série, observamos como a atual política desempenhada pelo governo Bolsonaro é solo de possibilidade para a veiculação de tal campanha, uma vez que, ao relacionarmos a dispersão dos enunciados, traçamos a regularidade do discurso de recusa e não cumprimento do papel de um bom governante porque, como diz Foucault, "o cuidado de si remete sempre a um estado político e erótico ativo $[\ldots]$ e um elo se fixa entre o cuidado de si e a atividade política".

\section{Conclusão}

Concluímos, com base na discussão aqui realizada, que a atual campanha feita pelo Ministério da Saúde funciona de modo semelhante a realizada por governos anteriores quando do início das infecções pelo HIV, campanhas essas que não focalizavam na prevenção e educação, mas em uma política que produz efeitos discursivos os quais tangenciam o medo e a repulsa. Analisamos, ainda, que o exercício do cuidado de si por 
Bruno Franceschini. “Da ‘Arqueologia do Saber' à Genealogia da Ética ou Quando o futuro repete o passado: o cuidado de si e as políticas públicas de saúde na atualidade

meio da educação sexual é um dos modos de o sujeito conduzir a si frente ao funcionamento das estratégias de poder centradas na biopolítica e no biopoder.

No tocante às práticas de liberdade e do cuidado de si, ponderamos que a educação sexual pode ser um modo de subjetivação do sujeito, uma vez que na relação consigo e com a verdade há a produção de subjetividade. Como argumenta Ribas (2017, p. 192), "nas relações que podemos estabelecer entre nós mesmos e a verdade ao refletirmos sobre a subjetividade é também preciso pensar as práticas possíveis de liberdade.”.

Por fim, em defesa de uma educação sexual, argumentamos em favor de um cuidado de si, de um cuidado da vida da população em que, entre as relações de poder e de resistência, no funcionamento do dispositivo de sexualidade, os sujeitos possam transformar-se a si e aos outros no exercício do dizer verdadeiro, na condução de suas condutas no âmbito de uma estilística da existência, como preconiza o pensamento foucaultiano, de modo que nesta forma de existência, de um modo outro de ser, a verdade possa, como o dispositivo, produzir formas outras de subjetividade em que os sujeitos passem a exercer o cuidado de si.

\section{Referências}

FOUCAULT, Michel. A ética do cuidado de si como prática da liberdade. In: Ditos \& Escritos V - Ética, Sexualidade, Política. Rio de Janeiro: Forense Universitária, 2004. FOUCAULT, Michel. A ordem do discurso. Tradução Laura Fraga de Almeida Sampaio. 18 ed. São Paulo: Edições Loyola, 2008.

FOUCAULT, Michel. A arqueologia do saber. Rio de Janeiro: Forense Universitária, 2009.

FOUCAULT, Michel. As Relações de Poder Passam para o Interior dos Corpos. In: Ditos \& Escritos IX. Rio de Janeiro: Forense Universitária, 2014.

FOUCAULT, Michel. Sobre a Genealogia da Ética: um Resumo do Trabalho em Curso. Ditos \& Escritos IX. Rio de Janeiro: Forense Universitária, 2014.

FOUCAULT, Michel. Em defesa da Sociedade - curso no Collège de France (19751976). São Paulo: Martins Fontes, 2016.

FOUCAULT, Michel. História da sexualidade: o uso dos prazeres. São Paulo: Paz e Terra, 2017.

FOUCAULT, Michel. As relações de poder perpassam para o interior dos corpos. Ditos \& Escritos IX. Rio de Janeiro: Forense Universitária, 2017. 
GUILHAUMOU, Jacques; MALDIDIER, Denise. Efeitos do arquivo: a análise do discurso no lado da história. In: Eni Puccinelli Orlandi. (Org.). Gestos de leitura: da história no discurso. Tradução Bethania S. C. Mariani et. al., 2 ed. Campinas: Editora da Unicamp, 1997.

SANCHES, Hoster Older. Dispositivo de sexualidade, sujeito e o acontecimento discursivo da AIDS no Brasil. 2014. 114f. Dissertção (Mestrado em Letras) - Programa de Pós-Graduação em Letras, Universidade Estadual de Maringá, Maringá, 2014.

RIBAS, Thiago Fortes. Práticas de liberdade em Foucault. Dois Pontos (UFPR) Digital, v. 14, p. 181-197, 2017. DOI: https://doi.org/10.5380/dp.v14i1.49491

Recebido em: 10 de novembro de 2019

Aceito em: 3 de dezembro de 2019 